\title{
МЕТОДИКА ВЫЯВЛЕНИЯ КОГНИТИВНЫХ СХЕМ ПРОСОЦИАЛЬНОГО ПОВЕДЕНИЯ 1
}

\section{METHODS FOR IDENTIFYING COGNITIVE PATTERNS OF PROSOCIAL BEHAVIOR ${ }^{2}$}

\section{A. Chernov}

Summary: Prosocial behavior is rarely studied in terms of the content and structure of a person's cognitive organization. Therefore, the article proposes a tool for identifying cognitive patterns of prosocial behavior. It was assumed that cognitive schemas contain various aspects of the experience of a person's prosocial activity. They concentrate knowledge, strategy and decision-making rules in pro-social situations, expectations about potential consequences, about the differentiation of areas, points of view, time parameters that are individual for a person.

The aim of the study was to develop, validate and standardize an original technique for diagnosing the severity of cognitive patterns of prosocial behavior. The study sample consisted of 200 people ( $50 \%$ of men, $50 \%$ of women aged 18 to 57). In the process of constructing the methodology, the retest reliability, obvious and meaningful validity were checked, which allows us to consider it a tool that adequately establishes individual differences in the severity of cognitive schemes of prosocial behavior. The developed methodology describes four factors corresponding to differentiated cognitive schemes of prosocial behavior: normativesituational scheme, dispositional scheme, affective-altruistic scheme, affective-normative scheme.

Keywords: prosocial behavior, cognitive schemes, normative-situational scheme, dispositional scheme, affective-altruistic scheme, affectivenormative scheme.

\author{
Чернов Александр Юрьевич \\ Д.nсх.н., доцент, с.н.с., Волгоградский государственный \\ университет, г. Волгоград. \\ achernov1@yandex.ru
}

Аннотация: Просоциальное поведение редко изучается с точки зрения содержания и структуры когнитивной организации человека. Поэтому в статье предложен инструмент для выявления когнитивных схем просоциального поведения. Предполагалось, что когнитивные схемы содержат различные аспекты опыта просоциальной активности личности.

В них сконцентрированы знания, стратегия и правила принятия решений в просоциальных ситуациях, ожидания 0 потенциальных последствиях, 0 дифференциации областей, точек зрения, временных параметров, которые являются индивидуальными для человека.

Целью исследования являлась разработка, валидизация и стандартизация оригинальной методики диагностики выраженности когнитивных схем просоциального поведения. Выборка исследования составила 200 человек (50\% мужчин, 50\% женщин в возрасте от 18 до 57 лет). В процессе конструирования методики осуществлена проверка ретестовой надежности, очевидной и содержательной валидности, что позволяет считать ее инструментом, адекватно устанавливающим индивидуальные различия выраженности когнитивных схем просоциального поведения.

Разработанная методика описывает четыре фактора, соответствующих дифференцированным когнитивным схемам просоциального поведения: нормативно-ситуативная схема, диспозициональная схема, аффективноальтруистическая схема, аффективно-нормативная схема.

Ключевые слова: просоциальное поведение, когнитивные схемы, нормативно-ситуативная схема, диспозициональная схема, аффективно-альтруистическая схема, аффективно-нормативная схема.

ка в следовании нормам просоциального поведения, в проявлении релевантных ему индивидуальных свойств личности, в принятии решений в ситуациях, требующих оказания помощи. [3; 8; 12]

Функцию актуализации опыта человека в контексте просоциального поведения, приведения его в соответствие с опознанными внешними условиями и с целями выполняет система когнитивной организации, центральным звеном которой являются когнитивные схемы. $[6 ; 7 ; 9 ; 11]$

В них сконцентрированы знания, стратегия и правила принятия решений в просоциальных ситуациях, ожидания о потенциальных последствиях, о дифференповедения. В рамках социокогнитивного подхода декларируется центральная роль личного опыта челове-

Работа выполнена при поддержке РФФИ грант № 19-013-00236 «Нормативная регуляция и саморегуляция просоциального поведения» 
циации областей, точек зрения, временных параметров, которые являются индивидуальными для человека. Актуальной в этом случае является разработка инструмента, позволяющего выявлять содержание и структуру когнитивных схем просоциального поведения. Теоретической основой такой работы было обобщение совокупности подходов, позволяющих реконструировать индивидуальную систему расчленений, противопоставлений и обобщений, лежащую в основе субъективных оценок, отношений и предсказаний.

Таким образом, целью исследования была разработка, валидизация и стандартизация оригинальной методики диагностики когнитивных схем просоциального поведения.

Задачи исследования:

1. Сформулировать перечень утверждений для измерения когнитивных схем просоциального поведения, исходя из научных представлений о данном феномене и из результатов качественного этапа исследования.

2. Сформировать репрезентативную выборку респондентов путем простого рандомизированного отбора.

3. Осуществить проверку очевидной, содержательной, конвергентной валидности и характеристик надежности методики.

\section{Этапы разработки методики}

Конструирование методики проходило в несколько этапов. На первом этапе ходе индивидуальных и групповых интервью был получен лингвистический материал, отражающий различные аспекты просоциального поведения. Для того, чтобы обеспечить соотвествие высказываний респондентов просоциальному контексту, им предлагался стимульный материал в виде короткого описания просоциальной ситуации: «Несколько лет назад я разговаривал с человеком, который время от времени появлялся в обществе с прикрепленной к пиджаку медалью «За спасение утопающих». Это произошло через десять дней после перенесенной им довольно сложной операции на желчном пузыре. Одновременно ему удалили аппендикс. В тот вечер он впервые, выписавшись из больницы, прогуливался со своей девушкой по многолюдному пляжу. Они услышали крик тонущей женщины. Тогда он прыгнул в воду, подплыл к ней и удерживал ее на плаву, пока не подоспели спасатели. Когда его самого вытащили из воды, он был чуть живой». Вопросы интервью формулировались так, чтобы ответы респондентов могли выражали их отношение к описываемым событиям с опорой на их личный опыт оказания помощи людям в различных ситуациях. Отдельные высказывания респондентов обобщались и соответствующим образом редактировались с тем, чтобы придать форму- лировкам пунктов опросника однозначный психологический смысл.

Первоначальная версия опросника включала 49 пунктов. Она была предложена непрофессиональным экспертам (5человек). Им предлагалось оценить утверждения с позиций их понятности, ясности, стилистической грамотности, адекватного подбора лексических форм.

Содержательная валидность, характеризующая степень релевантности и репрезентативности содержания утверждений опросника диагностируемой области, также определялась путем экспертных оценок. Трем экспертам - психологам было предложено оценить утверждения из первоначальной версии опросника на предмет их соответствия исследуемому феномену по четырехбалльной шкале (0 - не соответствует совсем, 1 - скорее не соответствует, 2 - скорее соответствует, 3 - абсолютно соответствует). По результатам работы экспертной группы был получен средний балл для каждого утверждения опросника, который, наряду с иными критериями, учитывался при отборе пунктов для его окончательной версии. Кроме этого, экспертам предлагалось определить, какой аспект просоциального поведения соответствует каждому пункту опросника.

На втором этапе осуществлялся отбор утверждений в окончательный вариант опросника, для чего были использованы следующие критерии:

1. Согласованность распределения эмпирических баллов каждого утверждения опросника с нормальным законом (после проведения процедуры эмпирической нормализации пункты методики, по которым показатели теста Колмогорова Смирнова $\mathrm{p}<0,005)$ исключались из перечня.

2. Средний показатель для каждого утверждения по оценкам экспертов, проводивших содержательную валидизацию опросника (в опросник включались утверждения со средним баллом не ниже 2,7).

Исследование проводилось на выборке из 140 человек (50\% мужчин и 50\% женщин) в возрасте от 18 до 57 лет, представляющих разные социально-демографические группы.

Третий этап конструирования методики был посвящен исследованию конвергентной валидности, направленной на оценку значений коэффициентов корреляции с переменными, с которыми он должен коррелировать, исходя из теоретических предположений. Использовались следующие методики:

1. Методика измерение просоциальных тенденций Г. Карло и Б.А. Рэндалл (адаптация Н.В. Кухтовой) выявляет различные типы проявления просоциальности: публичный тип, уступчивый тип, экстренный тип, эмоциональный тип, альтруистиче- 
ский тип. [4;10]

2. Методика «Справедливость-Забота» (С.В. Молчанов) предназначена для выявления уровня развития моральных суждений в соответствии с двумя основными периодизациями развития морального сознания: периодизацией Л. Кольберга и периодизацией К. Гиллиган. [5]

3. Методика «Социальные нормы просоциального

Когнитивные схемы просоциального поведения

(по результатам факторного анализа)

\begin{tabular}{|c|c|c|c|c|}
\hline Фактор и вес фактора & Пункты опросника & Значения & Когнитивная схема & $\begin{array}{c}\text { Атрибуты просоциального } \\
\text { поведения }\end{array}$ \\
\hline \multirow{6}{*}{$\begin{array}{c}\text { 0бъясняет } \\
23,5 \% \text { дисперсии }\end{array}$} & $\begin{array}{c}\text { Он чувствовал ответственность за жизнь человека, } \\
\text { попавшего в опасность }\end{array}$ & 0,649 & \multirow{6}{*}{$\begin{array}{l}\text { Ситуативно-норма- } \\
\text { тивная схема }\end{array}$} & Норма ответственности \\
\hline & $\begin{array}{c}\text { 0н убежден, что каждый человек имеет право и } \\
\text { возможность получить помощь в трудной ситуации. }\end{array}$ & 0,453 & & Норма справедливости \\
\hline & $\begin{array}{c}\text { Он убежден, что помогать попавшему в беду, долг } \\
\text { каждого порядочного человека. }\end{array}$ & 0,648 & & Норма ответственности \\
\hline & $\begin{array}{c}\text { Он видел, что попавший в беду человек очень } \\
\text { сильно нуждается в помощи. }\end{array}$ & 0,842 & & Вовлеченность в ситуацию \\
\hline & $\begin{array}{l}\text { Он понимал, что если не придет на помощь, все } \\
\text { закончится очень плохо. } \\
\end{array}$ & 0,795 & & Экстремальность ситуации \\
\hline & $\begin{array}{c}\text { 0н предполагал, что его действия не нанесут } \\
\text { вреда ему самому. }\end{array}$ & 0,699 & & Оценка ресурсов \\
\hline \multirow{5}{*}{$\begin{array}{c}\text { Второй } \\
\text { фактор } \\
\text { Объясняет } \\
\text { 14,8\% } \\
\text { дисперсии }\end{array}$} & $\begin{array}{c}\text { Проявление смелости и решительности в «острых» } \\
\text { ситуациях всегда были ему свойственны. }\end{array}$ & 0,738 & \multirow{5}{*}{$\begin{array}{l}\text { Диспозициональная } \\
\text { схема }\end{array}$} & Твердость характера \\
\hline & $\begin{array}{c}\text { Он всегда думал, что независимо от обстоятельств, } \\
\text { человек принимает решения, исходя из того, что сам } \\
\text { считает правильным и необходимым. }\end{array}$ & 0,706 & & Интернальность \\
\hline & $\begin{array}{c}\text { Он считал себя достаточно сильным, чтобы спра- } \\
\text { виться с опасностью, грозившей попавшему в беду } \\
\text { человеку и ему самому }\end{array}$ & 0,738 & & Уверенность \\
\hline & $\begin{array}{c}\text { Трудная, опасная ситуация всегда мотивировала его } \\
\text { на проявление его лучших качеств. }\end{array}$ & 0,689 & & Решимость \\
\hline & $\begin{array}{l}\text { В жизни он всегда руководствовался принципом } \\
\text { «Кто, если не я? ». }\end{array}$ & 0,456 & & Ответственность \\
\hline \multirow{5}{*}{$\begin{array}{c}\text { Третий } \\
\text { фактор } \\
\text { Объясняет } \\
\text { 9,6\% } \\
\text { дисперсии }\end{array}$} & $\begin{array}{c}\text { Спасая человека, попавшего в беду, он стремился } \\
\text { вызвать восхищение своей подруги. }\end{array}$ & 0,725 & \multirow{5}{*}{$\begin{array}{l}\text { Аффективно-альтруи- } \\
\text { стическая } \\
\text { схема }\end{array}$} & Гедонистический альтруизм \\
\hline & $\begin{array}{c}\text { Он знал, что его усилия не пропадут даром: другие } \\
\text { люди оценят его самопожертвование. }\end{array}$ & 0,761 & & Рациональный альтруизм \\
\hline & $\begin{array}{c}\text { Ему было легче подвергнуть себя опасности, чем } \\
\text { оставаться на месте и смотреть, как человек тонет. }\end{array}$ & & & Моральный альтруизм \\
\hline & Ему было жаль человека, попавшего в беду. & 0,568 & & $\begin{array}{c}\text { Спонтанное переживание } \\
\text { эмоций }\end{array}$ \\
\hline & $\begin{array}{c}\text { Эмоции «захлестнули» его, и он не отдавал отчета в } \\
\text { собственных действиях }\end{array}$ & 0,525 & & $\begin{array}{c}\text { Спонтанное переживание } \\
\text { эмоций }\end{array}$ \\
\hline \multirow[t]{4}{*}{$\begin{array}{l}\text { Четвертый } \\
\text { фактор }\end{array}$} & $\begin{array}{l}\text { В этот момент он еще раз пережил страх, который } \\
\text { испытывал перед операцией, и почувствовал то, что } \\
\text { переживает тонущий человек. }\end{array}$ & 0,707 & \multirow{4}{*}{$\begin{array}{l}\text { Нормативно-аффек- } \\
\text { тивная }\end{array}$} & Эмпатия \\
\hline & Он испытал такое же отчаяние, как тонущий человек. & 0,644 & & Эмпатия \\
\hline & $\begin{array}{c}\text { Он считал, что было бы не справедливо, если бы } \\
\text { человек погиб по собственной неосторожности или } \\
\text { вследствие стечения обстоятельств. }\end{array}$ & 0,731 & & Норма справедливости \\
\hline & $\begin{array}{c}\text { Он убежден, что каждый человек имеет право и воз- } \\
\text { можность получить помощь в трудной ситуации. }\end{array}$ & 0,514 & & Норма справедливости \\
\hline
\end{tabular}


поведения» (И.А. Фурманов, Н.В. Кухтова), направленная на изучение позиций присвоения социальных норм и построения межличностных отношений на основе норм, оказывающих влияние на просоциальную направленность поведения: норма социальной ответственности, норма взаимности, норма справедливости, норма «затраты» и «вознаграждения».

По результатам данного этапа получена окончательная версия методики выявления когнитивных схем просоциального поведения. Она включает 25 утверждений. Надежность результатов при повторном предъявлении одним и тем же респондентам из случайной выборки $(\mathrm{N}=40)$ через две недели после первого предъявления составила á=0, 92.

Для выявления структуры и содержания когнитивных схем саморегуляции просоциального поведения был проведен факторный анализ результатов, полученных при использовании разработанной методики. Результаты объясняют 56,7\% дисперсии, мера адекватности выборки Кайзера-Майера-Олкина = 0,825, критерий сферичности Бартлетта <0, 001. Результаты факторного анализа приведены в Таблице 1.

\section{Обсужкение результатов исследования}

Результаты факторного анализа когнитивных схем саморегуляции просоциального поведения позволяют сформулировать ряд суждений, отражающих их структурные и содержательные свойства.

Первая разновидность схем образована элементами, представляющими нормативные и ситуативные аспекты просоциального поведения. Соответственно, она названа «ситуативно-нормативная» схема (23,5\% дисперсии). Ведущим элементом этой схемы является атрибут «вовлеченность в ситуацию» (собственное значение $=0,842$ ). Вовлеченность в данном случае, означает, что человек, оказывающий помощь, осознает значения специфических социальных стимулов и осведомлен действиях, которые он собирается совершить и о месте этих действий в более широком социальном контексте. Кроме этого, значение имеют восприятие того, насколько экстремальна просоциальная ситуация $(0,795)$ и оценка собственных возможностей оказать помощь $(0,699)$. Нормативная составляющая этой разновидности когнитивных схем представлена нормой ответственности $(0,649)$ и 0,648 и нормой справедливости $(0,453)$.

Вторая разновидность схем - диспозициональная схема (14,8\% дисперсии). В ней отражены черты и свойства личности, ассоциируемые с просоциальным поведением: твердость характера $(0,738)$, уверенность
(0,739), интернальность $(0,796)$, решимость $(0,689)$, ответственность $(0,456)$. Ведущими элементами этой схемы являются «твердость характера» и «решимость».

Третья разновидность когнитивных схем просоциального поведения названа «аффетивно-альтруистичекой» (9,6\% дисперсии), так как ее структуру образуют различные виды альтруизма в сочетании с сопутствующими просоциальному поведению эмоциями. Ведущее положение в этом факторе занимает «рациональный альтруизм» $(0,761)$. Буквальное определение альтруизма - ориентация на интересы и потребности другого человека, а не свои собственные. В этом случае альтруизм тождественен действию по оказанию любой помощи, сопровождаемой скрытым личным мотивом. Тогда альтруизм имеет смысл только в связи с реализацией собственных интересов и удовлетворением собственных потребностей. Другими атрибутами альтруизма в этой схеме являются «гедонистический альтруизм» $(0,725)$ и «моральный альтруизм» $(0,502)$. Гедонистический альтруизм подразумевает получение удовольствия от помощи другим людям. Однако нельзя игнорировать, что любое удовольствие - это наше собственное удовольствие. Тогда не важно, направлены ли усилия человека на то, чтобы доставить радость и удовольствие окружающим людям. Смысл этой активности все равно заключается в удовлетворении собственных потребностей и интересов. Она не более, чем компромисс между различными векторами мотивации. Моральный альтруизм. понимается как феномен, регулирующий социальное поведение человека в соответствии с его системой ценностей. Как следствие, моральная сторона альтруизма соотносится с пониманием человеком своих обязательств перед другими людьми и своей ответственности перед ними вне зависимости от фактов, характеризующих конкретную ситуацию. Действительно, многие современные теории морали отождествляют альтруизм и нравственность, которые, в свою очередь, составляют предмет ответственности перед другими людьми. Аффективный элемент просоциального поведения представлен в этой схеме атрибутом «спонтанное переживание эмоций» $(0,568$ и 0, 502).

Четвертая схема - нормативно-аффективная» $(8,8 \%$ дисперсии). Именно в ней проявлен атрибут эмпатии $(0,707$ и 0,644) в сочетании с нормой справедливости $(0,731$ и 0,514$)$.

Логично утверждать, что каждая схема имеет средний показатель выраженности в выборке респондентов. Средний показатель складывается из суммы средних значений относящихся к схеме пунктов опросника или составляющих ее атрибутов просоциального поведения. Тогда:

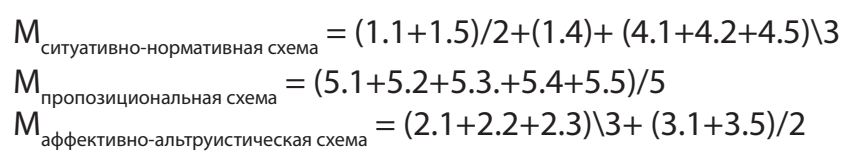


Таблица 2

Средние значения показателей когнитивных схем саморегуляции просоциального поведения

\begin{tabular}{|c|c|c|c|c|c|}
\hline Когнитивные схемы & $\mathrm{N}$ & Минимум & Максимум & Среднее значение & Стандартная отклонения \\
\hline Ситуативно-нормативная схема & 200 & 9,50 & 30,00 & 23,6767 & 4,91018 \\
\hline Диспозициональная схема & 200 & 1,00 & 10,00 & 6,8880 & 2,09960 \\
\hline Аффективно-альтруистическая схема & 200 & 4,00 & 20,00 & 11,5317 & 3,30575 \\
\hline Нормативно-аффективная схема & 200 & 3,00 & 20,00 & 12,4400 & 4,05286 \\
\hline
\end{tabular}

$\mathrm{M}_{\text {нормативно-аффективная схема }}=(3.3+3.4) \backslash 2+(1.3+1.4) \backslash 2$

В Таблице 2 приведены средние значения показателей каждой схемы.

\section{Выво $\Delta ы$}

1. Методика диагностики когнитивных схем просоциального поведения является надежным и валидным инструментом, позволяющим качествен- но оценить их структуру и содержание.

2. Выявлена внутренне согласованная когнитивная структура просоциального поведения, включающая нормативно-ситуативную, диспозициональную, аффективно-альтруистическую и нормативно-аффетивную схемы.

3. Данная методика может применяться как в исследовательских, так и в диагностических целях.

\section{ЛИТЕРАТУРА}

1. Акимова М.К., Персиянцева С.В. Влияние нормативности и конкретно-ситуативных факторов на просоциальное поведение молодежи разных региональных выборок\\Мир педагогики и психологии. -2019. -№ 9 (38).- С. 118-127.;

2. Алтунина И.Р., Немов Р.С. Мотивы и мотивация социального поведения как проблема социально-психологических исследований ІСовременная социальная психология: теоретические подходы и прикладные исследования. - 2009.- № 1. С. 7-17.

3. Гофман И. Анализ фреймов: эссе об организации повседневного опыта. М.: Институт социологии РАН, 2003. - 752 с.

4. Кухтова Н.В. Адаптация методики «Измерение просоциальных тенденций» (Г. Карло, Б.А. Рэндалл)\Вестник гродненского государственного университета имени Янки Купалы. - Серия 3. Филология. Педагогика. Психология. - 2013. - №2 (113). - С. 102-107.

5. Молчанов С.В. Морально-ценностные ориентации как функция социальной ситуации развития в подростковом и юношеском возрастеІККультурно-историческая психология. -2007. - № 1.- С. 73-78.

6. Плотников М.В. Индивидуальные социально-психологические механизмы социального поведения человека||Вестник Нижегородского университета им. Н.И. Лобачевского. - 2011. - № 4-1. -С. 361-367.

7. Шилкина Н.Е. Основания типизации социального поведения и понятийный аппарат исследования социального поведения в социологии ІСоциология в современном мире: наука, образование, творчество. - 2009.- № 1. -С. 180-186.

8. A Sociocognitive Approach to Social Norms. Contributors Nicole Dubois - Editor. New York, Routledge. - 2002. - p. 38.

9. Caigler V. Organization of self-knowledge: Features, functions, and flexibility In M. Leary J. P. Tangney (Eds.) Handbook of self and identity. - New York: Guilford, 2003. - pp. 47-67.

10. Carlo G, Hausmann A., Christiansen S., Randall B. Sociocognitive and Behavioral Correlates of a Measure of Prosocial Tendencies for Adolescents $\backslash \backslash$ Journal of Early Adolescence. - 2003. - 23:1. - pp. 107-134.

11. Dweck C.S., Leggett E.L. A social-cognitive approach to motivation and personalitylIPsychological Review.-1988. - N. 95. - pp. $256-273$.

12. Fiske S.T., Taylor S.E. Social Cognition. New York: McGraw-Hill, 1991. - 471 p.

13. Lampridis E., Papastylianou, D. Prosocial behavioural tendencies and orientation towards individualism-collectivism of Greek young adults $\mid$ International Journal of Adolescence and Youth. - 2014. - N. 4. - pp. 45-59.

(с) Чернов Александр Юрьевич (achernov1@yandex.ru). 